\title{
STUDI ANALISIS TERHADAP KEMAMPUAN SOFTSKILLS MAHASISWA FAKULTAS TEKNIK UNJ
}

\author{
Tuti Iriani ${ }^{1}$ \\ ${ }^{1}$ Dosen PTB FT UNJ, tutiiriani@unj.ac.id
}

\begin{abstract}
Abstrak
Penelitian ini bertujuan untuk memperoleh informasi tentang profil kemampuan soft skills yang dimiliki mahasiswa. Dalam penelitian ini, kemampuan soft skills mahasiswa diukur melalui kemampuan intrapersonal skills meliputi manajemen waktu, manajemen stress, manajemen perubahan, karakter personal, dan memiliki acun tujuan positif. Sedangkan interpersonal skill, meliputi kemampuan memotivasi, kemampuan memimpin/ teamwork, kemampuan presentasi, kemampuan komunikasi, kemampuan membuat relasi, dan kemampuan berbicara di depan umum. Hasil penelitian menunjukan bahwa Kemampuan Intrapersonal skills mahasiswa Fakultas Teknik UNJ dapat dikategorikan cukup baik untuk manajemen stress, manajemen perubahan, dan memiliki acuan tujuan positif. Namun demikian masih terdapat sebagian mahasiswa belum memiliki kesadaran diri terutama dalam manajemen waktu. Untuk kemampuan interpersonal skill mahasiswa Fakultas Teknik UNJ dapat dikategorikan cukup baik, seperti kemampuan memotivasi, kemampuan presentasi, kemampuan berkomunikasi, kemampuan membuat relasi. Sementara yang harus menjadi perhatian adalah kemampuan memimpin/ teamwork dan kemampuan berbicara di depan umum.
\end{abstract}

Kata kunci: Softskills, Interpersonal Skills, Intrapersonal Skills

\section{ANALYSIS STUDY ON SOFTSKILLS ABILITY OF ENGINEERING FACULTY STUDENT COLLEGE OF UNJ}

\author{
Tuti iriani, \\ ${ }^{1}$ Lecturer of PTB FT UNJ, tutiiriani@,unj.ac.id
}

\begin{abstract}
This study aims to obtain information related to students' soft skills ability profile. In this study, some soft skills were measured based on interpersonal skills ability such as time management, stress management, management of change, personal character, and positive objectives guidance. Meanwhile, interpersonal skills cover motivation skill, leadership/teamwork skill, presentation skill, good communication skill, building relationship skill, and public speaking skill. Results show that stress management, management of change, and positive objectives guidance is good enough among Faculty of Engineering student of UNJ. Yet, some students do not have self awareness regarding time management. Furthermore, students of Faculty of Engineering UNJ are noticed to have good motivation skill, presentation skill, good communication skill, and building relationship skill enough. Nonetheless, leadership/teamwork skill and public speaking skill need to have more concern.
\end{abstract}

Keywords: Media Learning, Audio Visual Media Based Learning, Building Construction Subjects 


\section{Pendahuluan}

Dunia kerja percaya bahwa sumber daya manusia yang unggul adalah mereka yang tidak hanya memiliki kemahiran hard skill saja tetapi juga piawai dalam aspek soft skillnya. Harus diakui bahwa para pengguna tenaga kerja kerap mengeluhkan lulusan perguruan tinggi (PT) yang kurang berkualitas, misalnya lulusan yang kurang tangguh, tidak jujur, cepat bosan, tidak bisa bekerja teamwork, sampai minim kemampuan berkomunikasi lisan dan menulis laporan dengan baik. Tentunya hal itu bisa menjadi bahan evaluasi, bukan hanya bagi kampus tertentu, tetapi juga seluruh kampus di tanah air tanpa terkecuali. Artinya, ada kecenderungan yang diberikan dibangku kuliah tidak sepenuhnya serasi dengan kebutuhan di lapangan kerja. Sebagian besar mateti yang disajikan, boleh dibilang berupa keterampilan keras (bard skill). Padahal, bukti-bukti menunjukkan penentu kesuksesan justru kebanyakan adalah keahlian yang tergolong lunak (soft skill). Sebagaimana survei dari National Association of College and Employee (NACE), USA (2002), kepada 457 pemimpin, tentang 20 kualitas penting seorang juara. Hasilnya berturut-turut adalah kemampuan komunikasi, kejujuran atau integritas, kemampuan bekerja sama, kemampuan interpersonal, beretika, motivasi atau inisiatif, kemampuan beradaptasi, daya analitik, kemampuan komputer, kemampuan berorganisasi, berorientasi pada detail, kepemimpinan, kepercayaan diri, ramah, sopan, bijaksana, indeks prestasi (IP $\geq$ $3,00)$, kreatif, humoris, dan kemampuan berwirausaha.

Sebagai seorang mahasiswa

ketercapaian Indeks Prestasi (IP) baru dapat menggambarkan kualitas seseorang dalam aspek kognitif dan belum bisa menunjukkan kualifikasi seseorang dalam bidang soft skill (Tarmidi, 2010). Hal ini sejalan dengan pendapat Setditjend Dikti (2010) sarjana lulusan perguruan tinggi di Indonesia masih sulit bersaing dengan lulusan luar negeri. Bukan dari sisi keilmuan atau kemampuan akademisnya, melainkan softs kill mereka yang lemah. Kelemahan mahasiswa kita justru dalam hal non teknis seperti kemampuan berbicara di depan umum, rasa percaya diri, interaksi terhadap perubahan yang cepat, inisiatif, kerjasama etika, leadership dan hal lainnya.

Survei yang dilakukan yang dilakukan Pusat Kurikulum DEPDIKNAS juga menyatakan bahwa kunci kesuksesan adalah $80 \%$ mindset soft skill dan 20\% technical skills (hard skill) (Dewiyani, 2011. Hal ini didukung berdasarkan penelitian di Harvard University Amerika Serikat, ternyata keberhasilan seseorang di masyarakat tidak ditentukan semata - mata oleh pengetahuan dan kemampuan teknis (hard skill) saja, tetapi lebih oleh kemampuan mengelola diri dan orang lain atau yang sering disebut sebagai karakter (soft skill) (Putra, 2005).

Soft skills adalah seperangkat kemampuan yang mempengaruhi bagaimana kita berinteraksi dengan orang lain. Menurut Patrick S. O'Brien dalam bukunya Making College Count, soft skill dapat dikategorikan ke dalam 7 area yang disebut Winning Characteristics, yaitu, communication skills, organizational skills, leadership, logic, effort, group skills, dan ethics. Kemampuan nonteknis yang tidak terlihat wujudnya (intangible) namun sangat diperlukan itu, disebut soft skill. Ketidakseimbangan pendidikan di ruang kuliah yang lebih bertumpu pada hard skill, tentu saja perlu segera diatasi, antara lain dengan memberikan bobot lebih kepada pengembangan soft skill. Implementasi soft skill tersebut dapat dilakukan baik melalui kurikulum maupun kegiatan ekstrakurikuler.

$\begin{array}{lrrr}\text { Lebih lanjut soft } & \text { skills } & \text { bisa } \\ \text { digolongkan } & \text { kedalan } & \text { dua } & \text { kategori } \\ \text { yaitu intrapersonal } & \text { skill } & \text { dan } \\ \text { interpersonal } & \text { skill. Intrapersonal } & \text { skill }\end{array}$ (keterampilan dalam mengatur dirinya sendiri) mencakup self awarenes, self confident, self assessment, trait \& preference, emotional awareness dan self skill (improveman, self control, trust, worthiness, time management, proactivity, conscience). Sedangkan interpersonal skill (keterampilan seseorang dalam berhubungan dengan orang lain) 
mencakup social awareness (political awareness, developing others, leveraging diversity, service orientation, empathy) dan socialskill (leadership, influence, communication, conflict management, cooperation, team work, synergy).

Mahasiswa Fakultas Teknik UNJ adalah mahasiswa yang dipersiapkan untuk menjadi sarjana kependidikan atau sarjana non kependidikan (ilmu murni) sesuai dengan bidang ilmu yang ditekuninya. Untuk sarjana kependidikan, mereka dipersiapkan menjadi guru Sekolah Menengah kejuruan yang harus memiliki kemampuan hard skill dan soft skill yang baik. Demikian juga lulusan sarjana non kependidikan yang dipersiapkan bekerja di Industri juga harus memiliki kemampuan hard skill dan soft skill yang dibutuhkan dalam dunia industri. Dalam pembelajaran di universitas, penilaian hasil belajar mahasiswa termasuk pada soft skill dan hard skill. Artinya, hard skill dibutuhkan dalam mengerjakan tugas dan ujian yang biasa diberikan dosen kepada mahasiswa untuk mendapatkan nilai yang maksimal. Sedangkan soft skills, dibutuhkan mahasiswa untuk memahami dan mematuhi etik, bersosialisasi dengan masyarakat baik teman sebaya, orang yang lebih tua, maupun kepada orang yang memiliki posisi yang tinggi di suatu lingkungan.

\section{Pengertian Softskills}

Menurut Sailah (2008) soft skills adalah "Personal and interpersonal behaviors that develop and maximize buman performance (eg. Coaching, team building, decision making, initiative. Sedangkan Klaus (2007) mengatakan bahwa "soft skills encompass personal, social, communication, and self management behaviours, theycover a wide spectrum: self awareness, trustwortbiness, conscientiousness, adaptability, critical thinking, organizational'. Hal ini sejalan dengan pendapat Tripathy (2006) yang menyatakan bahwa soft skills adalah kemampuan yang bersifat afektif yang dimiliki seseorang, meliputi: awareness, attitude, innitiative, emphathy, confidence, integrity, self-control, leadership, problem solving, risk taking and time management. Lebih lengkap
(Wicaksana) 2010), menyatakan bahwa Softskill dibedakan menjadi 2 kategori yaitu intrapersonal skills dan interpersonal skills. Interpersonal skills adalah ketrampilan seseorang dalam berhubungan dengan orang lain sedangkan intrapersonal skills adalah ketrampilan dalam mengatur dirinya sendiri yang mampu mengembangkan unjuk kerja secara maksimal. Intrapersonal skill bukan merupakan bagian dari karakter kepribadian yang bersifat bawaan, melainkan merupakan ketrampilan yang bisa dipelajari dan dilatih. Contoh: Intrapersonal skill yaitu time management, Stress management, Change management, Transforming beliefs, Transforming character, Creative thinking processes, Goal setting and life purpose dan Accelerated learning technicques.

Sedangkan Interpersonal Skill yang baik dapat dibangun dari kemampuan mengembangkan perilaku dan komunikasi yang asertif dan efektif, misalnya kemampuan, kesanggupan, kepandaian atau kemahiran seseorang dalam mengerjakan sesuatu. Seseorang yang memiliki interpersonal skill yang baik ditandai dengan memiliki konsep diri dan berkepribadian yang kuat; meningkatkan potensi diri menjadi pribadi yang mempunyai kompetensi dibidangnya; percaya diri dan mengasah kemampuan berkomunikasi; berpenampilan menarik dan menyenangkan; meningkatkan buman relations dalam kehidupan bermasyarakat dan organisasi dan meningkatkan kemampuan menjadi pemimpin dan dapat bekerjasama dalam team. Berdasarkan beberapa konsep soft skills diatas maka dapat dikatakan bahwa soft skills adalah kemampuan diluar kemampuan teknis dan akademis, yang lebih mengutamakan pada kemampuan intrapersonal dan interpersonal. Kedua kemampuan tersebut dapat dimiliki oleh seseorang melalui proses pembelajaran maupun proses pembiasan dalam kehidupan sehari-hari.

Secara garis besar, kemampuan intrapersonal mencakup aspek kesadaran diri (self awareness), yang didalamnya meliputi: 
kepercayaan diri, kemampuan untuk serta kemampuan mengendalikan emosional. Selain itu, kemampuan intrapersonal juga mencakup aspek kemampuan diri (self skill), yang didalamnya meliputi: upaya peningkatan diri, kontrol diri, dapat dipercaya, dapat mengelola waktu dan kekuatan, proaktif, dan konsisten. Disamping itu, soft skill juga bisa diterjemahkan ke dalam kemampuan yang melakukan penilaian dirinya, pembawaan, dimiliki oleh setiap individu untuk dapat mengembangan perasaan positif (positive feeling), selalu dan bisa untuk berfikir positif (positive thinking), dan mempunyai kebiasaan positif (positive habits) yang selalu diterapkan dalam kehidupan sehari-hari, baik untuk kepentingan diri sendiri maupun untuk orang lain (Sultoni, 2008).

\section{Indikator Soft Skills}

Tabel 1. Indikator soft skills menurut John Doe dalam Catur (2009)

\begin{tabular}{|c|c|c|}
\hline No. & Softskills & Keterangan \\
\hline 01 & Personal Effectiveness & $\begin{array}{l}\text { Kemampuan mendemontrasikan } \\
\text { kepercayaan-diri, ketangguhan, tanggung jawab } \\
\text { personal dan gairah untuk berprestasi }\end{array}$ \\
\hline 02 & Flexibility & $\begin{array}{l}\text { Ketangkasan dalam beradaptasi dengan perubahan } \\
\text { baru. }\end{array}$ \\
\hline 03 & Management & $\begin{array}{l}\text { Kemampuan mendapatkan hasil dengan } \\
\text { menggunakan sumberdaya yang ada, sistem dan } \\
\text { proses. }\end{array}$ \\
\hline 04 & Creativity/ Innovation & $\begin{array}{l}\text { Kemampuan memperbaiki hal-hal yang sudah lama, } \\
\text { kemampuan menciptakan dan menggunakan hal-hal } \\
\text { baru (sistem, pendekatan, konsep, metode, desain, } \\
\text { tehnologi, dan lain-lain) }\end{array}$ \\
\hline 05 & Futuristic thinking & $\begin{array}{l}\text { Kemampuan memproyeksikan hal-hal yang perlu } \\
\text { dicapai atau hal-hal yang berlum tercapai }\end{array}$ \\
\hline 06 & Leadership & $\begin{array}{l}\text { Kemampuan mencapai hasil dengan memberdayakan } \\
\text { orang lain. }\end{array}$ \\
\hline 07 & Persuasion & $\begin{array}{l}\text { Kemampuan dalam meyakinkan orang lain agar } \\
\text { berubah ke arah yang lebih baik }\end{array}$ \\
\hline 08 & Goal orientation & $\begin{array}{l}\text { Kemampuan dalam memfokuskan usaha untuk } \\
\text { mencapai tujuan, misi, atau target }\end{array}$ \\
\hline 09 & Continuous learning & $\begin{array}{l}\text { Kesediaan untuk menjalani proses learning, } \\
\text { memperbaiki diri dari praktek, menjalankan konsep } \\
\text { baru, tehnologi baru atau metode baru. }\end{array}$ \\
\hline 10 & Decision-making & $\begin{array}{l}\text { Kemampuan menempuh proses yang efektif dalam } \\
\text { mengambil keputusan }\end{array}$ \\
\hline 11 & Negotiation & $\begin{array}{l}\text { Kemampuan memfasilitasi kesepakatan antara dua } \\
\text { pihak atau lebih }\end{array}$ \\
\hline 12 & Written communication & $\begin{array}{l}\text { Kemampuan mengekspresikan pendapat atau } \\
\text { perasaan dengan bahasa tulis yang jelas dan mudah } \\
\text { dipahami orang lain }\end{array}$ \\
\hline 13 & $\begin{array}{l}\text { Employee } \\
\text { Coaching }\end{array}$ & $\begin{array}{l}\text { Kemampuan memfasilitasi dan mendukung kemajuan } \\
\text { orang lain }\end{array}$ \\
\hline 14 & Problem-solving & mengantisipasi, menganalisis, dan \\
\hline
\end{tabular}




\begin{tabular}{lll}
\hline 15 & Teamwork & $\begin{array}{l}\text { menyelesaikan masalah } \\
\text { Kemampuan dalam bekerjasama dengan orang lain } \\
\text { secara efektif dan produktif }\end{array}$ \\
\hline 16 & Presenting & $\begin{array}{l}\text { Kemampuan mengkomunikasikan pesan di depan } \\
\text { orang banyak secara efektif }\end{array}$ \\
\hline 17 & Diplomacy & $\begin{array}{l}\text { Kemampuan menangani kesulitan atau isu sensitif } \\
\text { secara diplomatif, bijak, efektif, dengan pemahaman } \\
\text { yang mendalam terhadap kultur, iklim dan politik } \\
\text { yang berkembang di tempat kerja. }\end{array}$ \\
\hline 18 & Conflict management & Kemampuan menyelesaikan konflik secara konstruktif \\
\hline 20 & Empatby & Kemampuan untuk bisa peduli pada orang lain \\
& & $\begin{array}{l}\text { Kemampuan mengantisipasi dan memenuhi } \\
\text { kebutuhan, keinginan dan harapan orang lain atau } \\
\text { pelanggan }\end{array}$ \\
\hline 21 & Planning / Organizing & $\begin{array}{l}\text { Kemampuan menggunakan logika, prosedur atau } \\
\text { sistem untuk mencapai sasaran }\end{array}$ \\
\hline 22 & Interpersonal skills & $\begin{array}{l}\text { Kemampuan berkomunikasi secara efektif, dan bisa } \\
\text { menjalin hubungan secara harmonis dengan orang } \\
\text { lain. }\end{array}$ \\
\hline 23 & Self-management & $\begin{array}{l}\text { Kemampuan mengontrol-diri atau mengelola potensi } \\
\text { dan waktu untuk mencapai hasil yang lebih bagus }\end{array}$ \\
\hline Personal Soft Skill Indicator, Jhon Doe, Performance DNA International, Ltd., (2001)
\end{tabular}

Sementara itu, Sharma (2009) menyebutkan bahwa soft skills adalah seluruh aspek dari generic skills yang juga termasuk elemenelemen kognitif yang berhubungan dengan non-academic skills. Ditambahkan pula bahwa, berdasarkan hasil penelitian, tujuh soft skills yang diidentifikasi dan penting dikembangkan pada peserta didik di lembaga pendidikan tinggi, meliputi; keterampilan dalam berkomunikasi (communicative skills), keterampilan berpikir dan menyelesaikan masalah (Thinking skills and Problem solving skills), kekuatan kerja tim (team work force), belajar sepanjang hayat dan pengelolaan informasi (life-long learning and information management), keterampilan wirausaha (entrepreneur skill), etika, moral dan profesionalisme (ethics, moral, and professionalism), dan keterampilan kepemimpinan (leadership skills).

Sharma (2009) mentabulasi elemen soft skills yang harus dimiliki dan baik dimiliki seperti ditunjukkan pada Tabel 2. Masing-masing soft skills didalamnya berisikan sub-skills yang dapat dikategorikan sebagai skills yang secara individu sangat dibutuhkan (must have) dan kategori sebagai skills yang baik untuk dimiliki (good to have). 
Tabel 2. Elemen soft skills yang harus dan baik untuk dimiliki (Sharma, 2009)

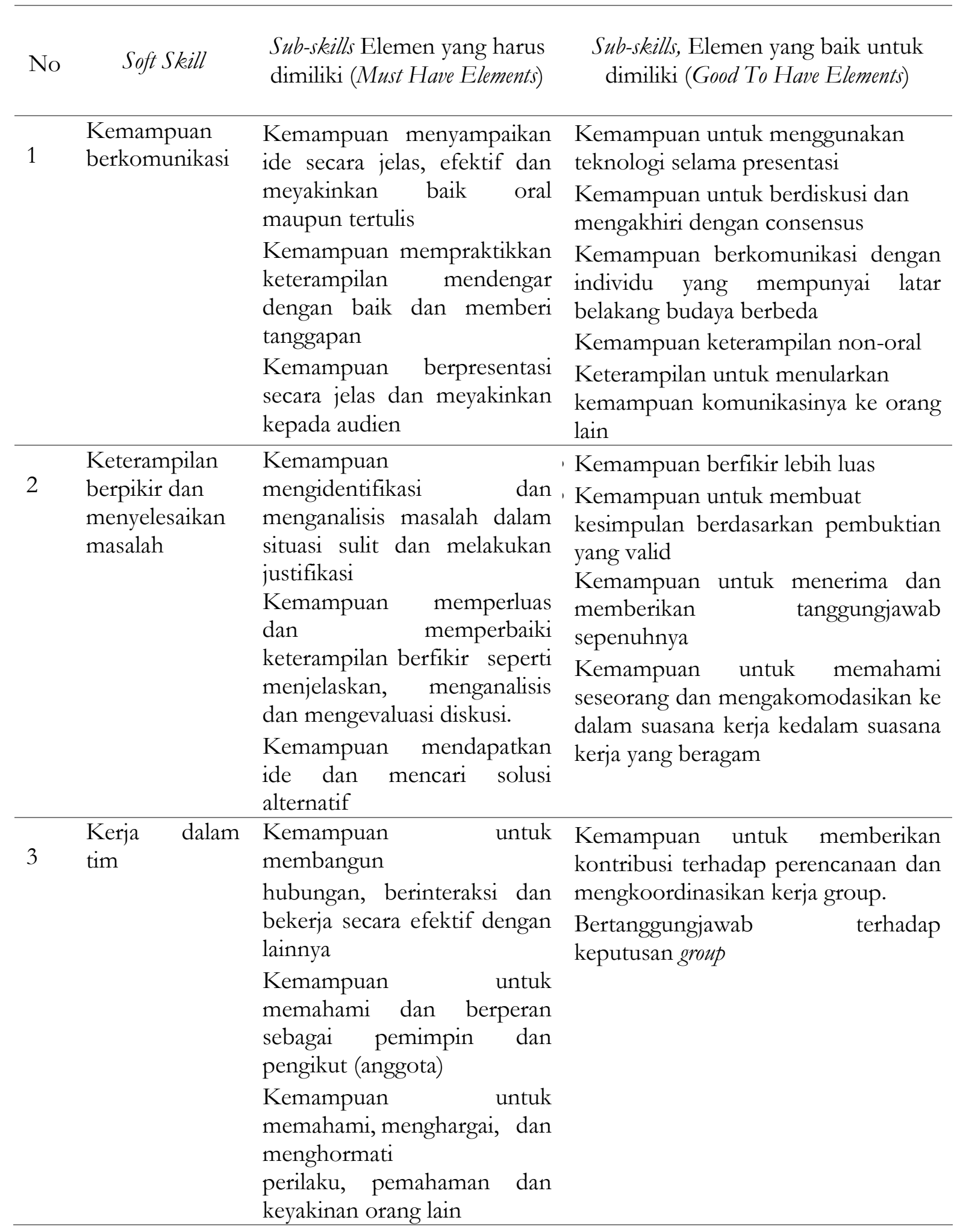




\begin{tabular}{|c|c|c|c|}
\hline \multirow[t]{2}{*}{4} & $\begin{array}{l}\text { Belajar } \\
\text { sepanjang hayat } \\
\text { dan }\end{array}$ & $\begin{array}{l}\text { Kemampuan untuk } \\
\text { mengelola informasi yang } \\
\text { relevan dari berbagai sumber }\end{array}$ & \multirow[t]{2}{*}{$\begin{array}{l}\text { Kemampuan.untuk.mengembangkan } \\
\text { keinginan untuk menginvestigasikan } \\
\text { dan mencari pengetahuan. }\end{array}$} \\
\hline & $\begin{array}{l}\text { pengelolaan } \\
\text { informasi }\end{array}$ & $\begin{array}{l}\text { Kemampuan untuk } \\
\text { menerima ide-ide baru }\end{array}$ & \\
\hline \multirow[t]{3}{*}{5} & $\begin{array}{l}\text { Keterampilan } \\
\text { kewirausahaan }\end{array}$ & $\begin{array}{l}\text { Kemampuan } \\
\text { mengidentifikasi }\end{array}$ & $\begin{array}{l}\text { Kemampuan untuk mengajukan } \\
\text { proposal peluang bisnis }\end{array}$ \\
\hline & & kerja & $\begin{array}{l}\text { Kemampuan untuk membangun, } \\
\text { mengeksprorasai dan mencari } \\
\text { peluang bisnis dan kerja }\end{array}$ \\
\hline & & & $\begin{array}{l}\text { Kemampuan untuk berwirausaha } \\
\text { sendiri }\end{array}$ \\
\hline \multirow[t]{2}{*}{6} & $\begin{array}{l}\text { Etika, moral } \\
\text { dam } \\
\text { profesionalisme }\end{array}$ & $\begin{array}{l}\text { Kemampuan } r \\
\text { memahami krisis ekonomi, } \\
\text { aspek social budaya secara } \\
\text { professional }\end{array}$ & $\begin{array}{l}\text { Kemampuan untuk mempratekan } \\
\text { etika perilaku di samping mempunyai } \\
\text { tanggung jawab terhadap masyarakat. }\end{array}$ \\
\hline & & $\begin{array}{l}\text { Kemampuan analisis untuk } \\
\text { membuat } \\
\text { pemecahan masalah terkait } \\
\text { dengan etika }\end{array}$ & \\
\hline \multirow[t]{2}{*}{7} & $\begin{array}{l}\text { Keterampilan } \\
\text { kepemimpinan }\end{array}$ & $\begin{array}{l}\text { Mempunyai pengetahuan } \\
\text { teori dasar kepemimpinan. }\end{array}$ & $\begin{array}{l}\text { Kemampuan untuk memahami dan } \\
\text { menjadi alternatif pemimpin dan }\end{array}$ \\
\hline & & $\begin{array}{l}\text { Kemampuan untuk } \\
\text { memimpin suatu project }\end{array}$ & \\
\hline
\end{tabular}

Ruben and DeAngelis (1998) dari hasil surveynya mengelompokkan kompetensi yang dibutuhkan agar seseorang dapat sukses meniti karir dan kehidupannya, yaitu kompetensi personal, komunikasi, organisasi, internasional/antar budaya dan domain, seperti ditunjukkan pada tabel dibawah ini:

Tabel 3. Kompetensi yang dibutuhkan untuk sukses dalam pekerjaan

(Ruben dan DeAngelis, 1998)

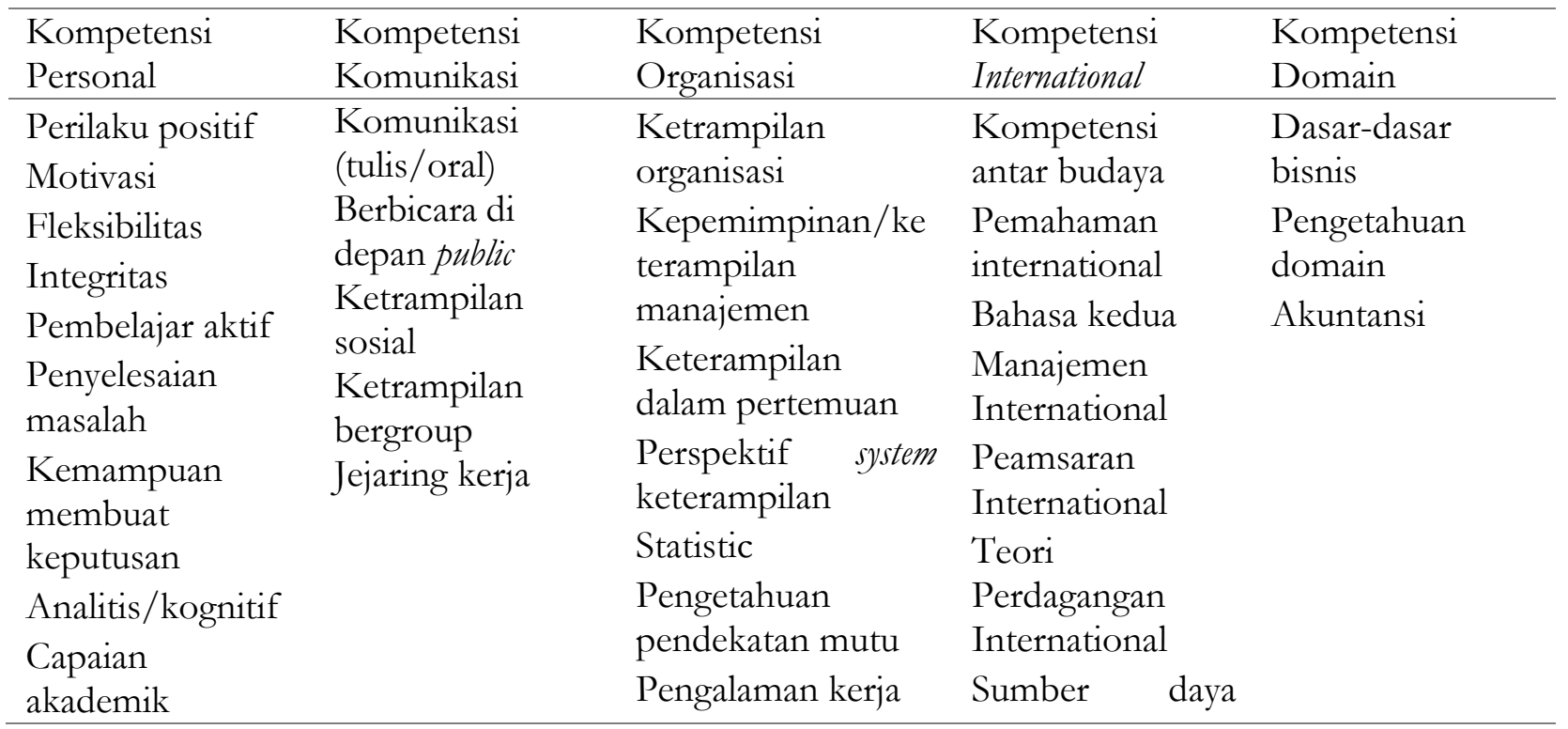




\begin{tabular}{lll}
\hline Komitmen untuk & Orientasi & manusia \\
berubah & pelanggan & International \\
Loyalitas & Aktivitas extra & \\
& curriculum & \\
& Pemahaman bisnis & \\
\hline
\end{tabular}

Puilam (2008) menyebutkan bahwa skills yang paling dicari oleh pemberi kerja adalah keterampilan komunikasi, integritas/kejujuran, keterampilan interpersonal, motivasi/inisiatif, etika kerja yang kuat, bekerja dalam tim, keterampilan komputer, analitis, fleksibilitas/adaptibilitas, dan detail oriented. Perlunya kemampuan soft skills juga diperkuat oleh hasil survei yang dilakukan National Association of Colleges and Employers (NACE) tahun 2002 di Amerika Serikat. Peter Vogt kemudian mengelompokkan hasil survei itu menjadi 10 kemampuan atau keterampilan yang diminta oleh pemberi kerja dari para pencari kerja. Tabel 4 menyajikan ke-10 kemampuan itu diurut berdasarkan skor.

Tabel 4. Kemampuan yang diperlukan dunia kerja menurut kepentingannya

\begin{tabular}{llc}
\hline No & Kemampuan/keterampilan & Skor kepentingan \\
\hline 1 & Kemampuan komunikasi & 4.69 \\
\hline 2 & Kejujuran/integritas & 4.59 \\
\hline 3 & Keammpuan bekerja sama & 4.54 \\
\hline 4 & Kemampuan interpersonal & 4.50 \\
\hline 5 & Beretika & 4.46 \\
\hline 6 & Motivasi/inisiatif & 4.42 \\
\hline 7 & Kemampuan beradaptasi & 4.41 \\
\hline 8 & Daya analitik & 4.36 \\
\hline 9 & Kemampuan computer & 4.21 \\
\hline 10 & Kemampuan berorganisasi & 4.05 \\
\hline 11 & Berorientasi pada detail & 4.00 \\
\hline 12 & Kepemimpinan & 3.97 \\
\hline 13 & Kepercayaan diri & 3.95 \\
\hline
\end{tabular}

Sumber: Hasil survey NACE USA (2002)

Di Indonesia tahun 2007, Pusat Data dan Analisis Tempo (PDAT) melakukan survey tentang karakter juara pilihan dunia kerja seperti disajikan pada Tabel 5.

Tabel 5. Peringkat Karakter Pencari Kerja yang Dituntut Dunia Kerja (PDAT, 2007)

\begin{tabular}{lll}
\hline No & Karakter Juara & Persentase \\
\hline 1 & Mau bekerja keras & 9.03 \\
\hline 2 & Kepercayaan diri tinggi & 8.75 \\
\hline 3 & Mempunyai visi kedepan & 8.37 \\
\hline 4 & Bisa bekerja dalam tim & 8.07 \\
\hline 5 & Memiliki perencanaan matang & 7.91 \\
\hline 6 & Mampu berpikir analitis & 7.82 \\
\hline 7 & Mudah beradaptasi & 7.2 \\
\hline 8 & Mampu bekerja dalam tekanan & 5.91 \\
\hline 9 & Cakap berbahasa inggris & 5.27 \\
\hline 10 & Mampu mengorganisasi pekerjaan & 5.26 \\
\hline
\end{tabular}




\section{Metode Penelitian}

Tujuan penelitian ini adalah untuk mengetahui profil kemampuan soft skill mahasiswa Fakultas Teknik UNJ. Sampel diambil secara random sampling, mahasiswa angkatan 2010 - 2013 dengan total 117 mahasiswa. Metode penelitian menggunakan metode survey. Pernyataan dalam kuesioner soft skills ini berdasarkan aspek pembagian soft skills yang terdiri atas intrapersonal skill dan interpersonal skill. Dari kedua indikator tersebut dibagi menjadi beberapa sub indikator. a. Indikator pertama yaitu intrapersonal skill, terdiri dari sub indikator, antara lain: manajemen waktu, manajemen stress, manajemen perubahan, karakter personal, dan memiliki acun tujuan positif.

b. Indikator kedua yaitu interpersonal skill, terdiri dari sub indikator, antara lain: kemampuan memotivasi, kemampuan memimpin/ teamwork, kemampuan presentasi, kemampuan komunikasi, kemampuan membuat relasi, dan kemampuan berbicara di depan umum.

\section{Hasil Penelitian}

\section{Intrapersonal Skills}

Tabel 6. Kemampuan Intrapersonal Skills

\begin{tabular}{|c|c|c|c|c|c|c|c|}
\hline \multirow[t]{2}{*}{ Indikator } & \multirow{2}{*}{$\begin{array}{l}\text { Sub } \\
\text { Indikator }\end{array}$} & \multirow[t]{2}{*}{ No. } & \multirow[t]{2}{*}{ Pernyataan } & \multicolumn{4}{|c|}{ Persentase $(\%)$} \\
\hline & & & & SS & $\mathrm{S}$ & TS & STS \\
\hline \multirow{5}{*}{ 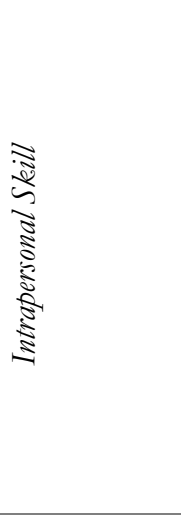 } & \multirow{5}{*}{ 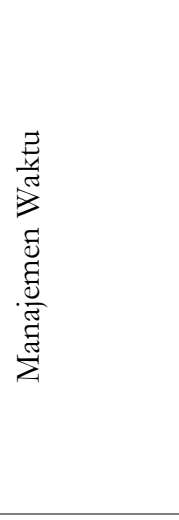 } & 1. & $\begin{array}{l}\text { Saya menulis jadwal kegiatan yang akan } \\
\text { dilaksanakan esok }\end{array}$ & 11,7 & 54,4 & 28,1 & 5,8 \\
\hline & & 2. & $\begin{array}{l}\text { Saya memiliki jadwal untuk belajar secara } \\
\text { teratur }\end{array}$ & 7 & 49,7 & 39,2 & 4,1 \\
\hline & & 3. & $\begin{array}{l}\text { Saya tidak terbiasa belajar jika hanya ada tugas } \\
\text { atau ujian }\end{array}$ & 6,4 & 42,1 & 48 & 3,5 \\
\hline & & 4. & $\begin{array}{l}\text { Saya tidak kesulitan mengatur jadwal kuliah dan } \\
\text { jadwal kegiatan lain (misalkan: bekerja, } \\
\text { berorganisasi, membantu pekerjaan rumah, } \\
\text { dsb) }\end{array}$ & 11,7 & 55 & 29,2 & 4,1 \\
\hline & & 5. & $\begin{array}{l}\text { Saya mampu menyelesaikan tugas kuliah } \\
\text { dengan baik dan mengumpulkannya sesuai } \\
\text { dengan jadwal yang telah ditentukan }\end{array}$ & 18,7 & 67,8 & 12,3 & 1,2 \\
\hline \multirow{4}{*}{ 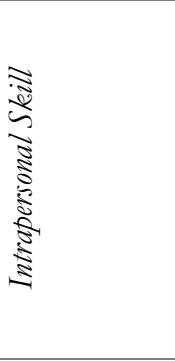 } & \multirow{4}{*}{ 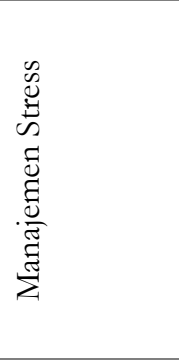 } & 6. & $\begin{array}{l}\text { Saya mampu mengendalikan diri jika saya } \\
\text { terlibat masalah }\end{array}$ & 21,1 & 64,3 & 12,8 & 1,8 \\
\hline & & 7. & $\begin{array}{l}\text { Saya selalu berbagi jika ada masalah kepada } \\
\text { orang-orang terdekat (orang tua, sahabat, pacar, } \\
\text { dsb) }\end{array}$ & 26,9 & 49,1 & 19,3 & 4,7 \\
\hline & & 8. & $\begin{array}{l}\text { Saya berusaha mencari solusi sendiri atas } \\
\text { permasalahan saya }\end{array}$ & 25,1 & 54,4 & 19,9 & 0,6 \\
\hline & & 9. & $\begin{array}{l}\text { Saya mau mendengar saran yang diberikan } \\
\text { kepada saya atas permasalahan saya }\end{array}$ & 40,4 & 54,4 & 4,7 & 0,6 \\
\hline \multirow[t]{2}{*}{$\begin{array}{l}\text { Intrapersonal } \\
\text { Skill }\end{array}$} & \multirow[t]{2}{*}{$\begin{array}{l}\text { Manajemen } \\
\text { Perubahan }\end{array}$} & 10. & $\begin{array}{l}\text { Saya mampu beradaptasi dengan perubahan } \\
\text { baru yang ada di kampus }\end{array}$ & 15,2 & 71,9 & 12,3 & 0,6 \\
\hline & & 11. & $\begin{array}{l}\text { Saya cepat berdaptasi dengan orang-orang yang } \\
\text { baru dikenal }\end{array}$ & 12,3 & 59,1 & 28 & 0,6 \\
\hline \multirow{4}{*}{ 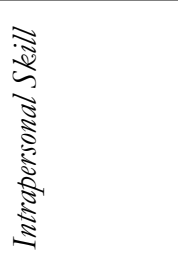 } & \multirow{4}{*}{ 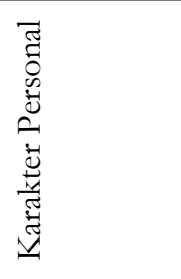 } & 12. & $\begin{array}{l}\text { Saya mencari sumber informasi lain jika di } \\
\text { perkuliahan terdapat materi yang belum saya } \\
\text { mengerti }\end{array}$ & 21,1 & 67,8 & 9,9 & 1,2 \\
\hline & & 16. & Saya mampu memotivasi diri saya sendiri & 24,6 & 63,2 & 10,5 & 1,7 \\
\hline & & 17. & Saya memiliki kepercayaan diri yang tinggi & 11,7 & 55,6 & 31 & 1,7 \\
\hline & & 18. & $\begin{array}{l}\text { Saya akan terus berjuang untuk menyelesaikan } \\
\text { studi saya }\end{array}$ & 52,6 & 45 & 1,2 & 1,2 \\
\hline
\end{tabular}




\begin{tabular}{|c|c|c|c|c|c|c|c|}
\hline & & 20. & $\begin{array}{l}\text { Saya menikmati proses perkuliahan di jurusan } \\
\text { yang saya pilih sekarang }\end{array}$ & 20,5 & 61,4 & 16,4 & 1,8 \\
\hline & & 30. & $\begin{array}{l}\text { Saya yakin dengan aktif di organisasi, softskills } \\
\text { saya bertambah }\end{array}$ & 19,9 & 49,7 & 26,3 & 4,1 \\
\hline \multirow[t]{2}{*}{$\begin{array}{l}\text { Intrapersonal } \\
\text { Skill }\end{array}$} & $\begin{array}{l}\text { Memiliki } \\
\text { Acuan }\end{array}$ & 14. & Saya memiliki cita-cita yang jelas & 46,8 & 40,4 & 11,6 & 1,2 \\
\hline & $\begin{array}{l}\text { Tujuan } \\
\text { Positif }\end{array}$ & 15. & $\begin{array}{l}\text { Saya sudah menyusun langkah-langkah jangka } \\
\text { panjang untuk mewujudkan cita-cita saya }\end{array}$ & 31,6 & 51,5 & 16,3 & 0,6 \\
\hline
\end{tabular}

Berdasarkan tabel di atas untuk Intrapersonal skills, menunjukkan bahwa kemampuan menyelesaikan tugas tepat waktu dan mengumpulkan sesuai dengan jadwal yang telah ditentukan menepati persentase tertinggi yaitu $54.4 \%$ setuju dan $28.1 \%$ tidak setuju. Untuk responden yang memiliki jadwal belajar yang teratur $49.7 \%$ menyatakan setuju memiliki jadwal yang tetap tetapi 39.2\% menyatakan tidak setuju. Diikuti dengan kemampuan mengatur waktu antara bekerja, berorganisasi, kuliah dan aktivitas lain yaitu 55\% setuju dan $29.2 \%$ tidak setuju.

Untuk kemampuan dalam manajemen stress, kemampuan dalam mengendalikan diri jika ada masalah menempati persentase tertinggi yaitu $64,3 \%$. Diikuti dengan kemampuan mencari solusi sendiri $54.4 \%$ dan tidak berusaha mencari solusi sendiri $19.9 \%$. Sementara mau mendengar saran dari orang lain adalah lebih dari 50\%.

Selanjutnya untuk kemampuan Manajemen Perubahan, data menunjukan bahwa kemampuan beradaptasi dengan perubahan baru yang ada di kampus menempati persentase tertinggi yaitu $71.9 \%$ dan diikuti dengan kemampuan beradaptasi dengan orang lain $59.1 \%$.

Pada sub indikator Karakter Personal, data menunjukan bahwa kemampuan mencari informasi jika ada materi yang belum dipahami menempati persentase tertinggi yaitu $67.8 \%$, diikuti kemampuan memotivasi diri $63.2 \%$, menikmati proses perkuliahan yang dipilih $61.4 \%$ dan memiliki kepecayaan diri yang tinggi 55.6\%.

Selanjutnya untuk memiliki acuan tujuan positif, menunjukkan $46.8 \%$ menyatakan sangat setuju memiliki cita-cita yang jelas dan 51.5\% sudah menyusun langkah-langkah jangka panjang untuk mewujudkannya.

\section{Interpersonal Skill}

Tabel 7. Interpersonal Skill

\begin{tabular}{|c|c|c|c|c|c|c|c|}
\hline \multirow{2}{*}{ Indikator } & \multirow{2}{*}{ Sub Indikator } & \multirow{2}{*}{ No. } & \multirow{2}{*}{ Pernyataan } & \multicolumn{4}{|c|}{ Persentase (\%) } \\
\hline & & & & SS & S & TS & STS \\
\hline $\begin{array}{l}\text { Interperson } \\
\text { al Skill }\end{array}$ & $\begin{array}{l}\text { Kemampuan } \\
\text { Memotivasi }\end{array}$ & 19. & $\begin{array}{l}\text { Saya mampu meyakinkan/ memotivasi teman } \\
\text { saya agar berubah ke arah yang lebih baik }\end{array}$ & 19,9 & 61,4 & 16,4 & 2,3 \\
\hline \multirow[t]{3}{*}{$\begin{array}{l}\text { Interperson } \\
\text { al Skill }\end{array}$} & $\begin{array}{l}\text { Kemampuan } \\
\text { Memimpin/ } \\
\text { teamwork }\end{array}$ & 21. & $\begin{array}{l}\text { Saya berambisi untuk menjadi pemimpin } \\
\text { dalam suatu kelompok }\end{array}$ & 8,8 & 39,8 & 47,4 & 4,1 \\
\hline & & 22. & $\begin{array}{l}\text { Saya merasa mampu untuk memimpin dalam } \\
\text { suatu kelompok }\end{array}$ & 6,4 & 53,8 & 36,3 & 3,5 \\
\hline & & 32. & $\begin{array}{l}\text { Saya mampu bekerjasama dengan orang lain } \\
\text { secara efektif dan produktif }\end{array}$ & 19,8 & 74,3 & 5,3 & 0,6 \\
\hline $\begin{array}{l}\text { Interperson } \\
\text { al Skill }\end{array}$ & $\begin{array}{l}\text { Kemampuan } \\
\text { Presentasi }\end{array}$ & 25. & $\begin{array}{l}\text { Saya mampu mempresentasikan tugas/ hasil } \\
\text { penelitian saya di depan orang banyak secara } \\
\text { efektif }\end{array}$ & 9,4 & 63,2 & 26,8 & 0,6 \\
\hline
\end{tabular}




\begin{tabular}{|c|c|c|c|c|c|c|c|}
\hline $\begin{array}{l}\text { Interperson } \\
\text { al Skill }\end{array}$ & $\begin{array}{c}\text { Kemampuan } \\
\text { Berkomunikasi }\end{array}$ & 23. & $\begin{array}{l}\text { Saya terbiasa berdiskusi dengan teman-teman } \\
\text { atau dosen saya }\end{array}$ & 7,6 & 70,8 & 19,9 & 1,8 \\
\hline & & 27. & $\begin{array}{l}\text { Saya memiliki hubungan yang baik dengan } \\
\text { teman-teman di lain jurusan, fakultas, bahkan } \\
\text { universitas lain }\end{array}$ & 42,1 & 52,6 & 4,1 & 1,2 \\
\hline & & 28. & $\begin{array}{l}\text { Saya memiliki hubungan yang baik dengan } \\
\text { beberapa dosen }\end{array}$ & 5,8 & 73,1 & 18,7 & 2,4 \\
\hline \multirow[t]{2}{*}{$\begin{array}{l}\text { Interperson } \\
\text { al Skill }\end{array}$} & $\begin{array}{l}\text { Kemampuan } \\
\text { Membuat }\end{array}$ & 26. & $\begin{array}{l}\text { Saya memiliki teman-teman di lain jurusan, } \\
\text { fakultas, bahkan universitas lain }\end{array}$ & 43,9 & 53,2 & 1,8 & 1,2 \\
\hline & & 29. & $\begin{array}{l}\text { Saya mengikuti organisasi internal/ eksternal } \\
\text { kampus }\end{array}$ & 10,5 & 35,1 & 45,6 & 8,8 \\
\hline $\begin{array}{l}\text { Interperson } \\
\text { al Skill }\end{array}$ & $\begin{array}{l}\text { Kemampuan } \\
\text { Berbicara di } \\
\text { depan umum }\end{array}$ & 24. & Saya mampu berbicara di depan umum & 7,6 & 60,2 & 30,6 & 1,6 \\
\hline
\end{tabular}

Berdasarkan data diatas menunjukan soft skills pada kemampuan kemampuan memotivasi diri menunjukan lebih dari $60 \%$ responden mampu meyakinkan atau memotivasi orang lain agar berubah ke arah yang lebih baik. Namun masih terdapat sekitar 16\% yang belum mampu melakukan hal tersebut.

Selanjutnya pada sub indikator Kemampuan Memimpin/ teamwork data menunjukan lebih dari $50 \%$ mampu menjadi pemimpin, dan $74.3 \%$ menyatakan mampu bekerjasama dengan orang lain.

Untuk kemampuan melakukan presentasi, $63.2 \%$ menyatakan setuju tetapi $26.8 \%$ dari responden menyatakan belum mampu.

\section{Pembahasan}

Kemampuan soft skills yang terdiri dari kemampuan intrapersonal skills dan kemampuan interpersonal skill sangat penting dalam kehidupan. Amstrong (2004) meyatakan bahwa kemampuan intrapersonal merupakan kemampuan memahami diri sendiri dan bertindak berdasarkan pemahaman tersebut. Dengan kata lain kemampuan intrapersonal meliputi kemampuan yang berkaitan dengan keadaan manusia secara internal seperti refleksi diri, berpikir meta kognisi dan menyadari adanya
Demikian juga untuk keampuan berkomunikasi, data menunjukan lebih dari $70 \%$ dari responden menyatakan bahwa biasa berdiskusi dengan kelompok, memiliki hubungan yang baik dengan teman dan juga dosen. Hal tersebut diperkuat dengan pernyataan mereka memiliki kemampuan membuat relasi yang ditunjukan dengan data lebih dari 50\%. Namun $45.6 \%$ dari responden menyatakan tidak tergabung dalam organisasi internal maupun eksternal kampus.

Selanjutnya pada Kemampuan Berbicara di Depan Umum, $60.2 \%$ responden menyatakan mampu berbicara di depan umum. Walaupun demikian 30\% dari responden menyatakan belum mampu berbicara di depan umum (public speaking).

kenyataan spiritual. Berdasarkan hasil penelitian diatas menunjukan bahwa manajemen stress, manajemen perubahan, karakter persona dan memiliki acuan tujuan positif dalam kategori cukup baik.

Walaupun demikian hasil penelitian juga menunjukan terdapat lebih dari 25\% menyatakan belum dapat menyelesaikan tugas dengan tepat waktu. $39.2 \%$ menyatakan tidak memiliki jadwal yang tetap untuk belajar dan 29\% menyatakan kesulitan dalam mengatur waktu antara 
belajar, bekerja dan organisasi. Sebagaimana yang dikatakan oleh Wicaksana (2010) bahwa Intrapersonal skill bukan merupakan bagian dari karakter kepribadian yang bersifat bawaan, melainkan merupakan keterampilan yang bisa dipelajari dan dilatih. Dengan demikian, bagi mahasiswa yang belum dapat mencapai kemampuan intrapersonal tersebut maka perlu adanya upaya didalam memahami diri sendiri dan menumbuhkan kesadaran pentingnya mengatur waktu.

Untuk Interpersonal skill, Menurut Hayes (2002) interpersonal skill adalah goaldirected behaviour yang digunakan dalam interaksi tatap muka, yang efektif dalam mewujudkan keadaan yang diinginkan. Rungapadiachy (1999) mengatakan bahwa interpersonal skill dapat didefinisikan sebagai suatu keterampilan yang diperlukan untuk berkomunikasi secara efektif dengan seseorang atau kelompok orang.

Berdasarkan penelitian ini, data menunjukan bahwa kemampuan memotivasi diri, kemampuan meyakinkan atau memotivasi orang lain agar berubah ke arah yang lebih baik dalam kategori cukup baik. Demikian juga pada kemampuan memimpin/ teamwork data dan bekerjasama dengan orang lain. Demikian juga untuk kemampuan berkomunikasi, melakukan presentasi, berdiskusi dengan kelompok, memiliki hubungan yang baik dengan teman dan juga dosen dalam kategori baik. Artinya bahwa kemampuan interpersonal skill yang dimiliki mahasiswa Fakultas Teknik dalam kategori baik. Walaupun tidak dapat dipungkiri, data juga menunjukan 25\% dari responden menyatakan bahwa belum mampu melakukan presentasi dengan baik, tidak mengikuti organisasi baik di dalam dan diluar kampus serta ketidakmampuan untuk berbicara di depan umum. Temuan ini menjadi menarik, karena sebagai seorang mahasiswa seyogyanya banyak kesempatan dan peluang untuk mengasah diri dalam meningkatkan kemampuan Interpersonal skill. Misalnya dengan menigkuti berbagai ajang lomba kemahasiswaan atau mengikuti organisasi kemahasiswaan. Sebagaimana Daniel Goleman (1995) mengemukakan bahwa kemampuan interpersonal juga termasuk bagian dari emotional intelligence. Goleman menyatakan ada lima konstruk kecerdasan emosional; yaitu kesadaran diri, mengelola emosi, motivasi diri, empati dan membina hubungan. Kemampuan interpersonal atau membina hubungan adalah kemampuan untuk menjalin hubungan dengan orang lain. Kemampuan ini meliputi kemampuan berempati, berkomunikasi dan mempengaruhi orang lain, merundingkan pemecahan masalah, memimpin dan mengorganisasikan kelompok, membina dan menjalin hubungan, dan kemampuan bekerjasama. Dengan demikian, kesadaran diri untuk meningkatkan kemampuan diri menjadi hal yang utama.

\section{Kesimpulan}

Penelitian ini menghasilkan beberapa kesimpulan diantaranya:

1. Kemampuan Intrapersonal skill mahasiswa Fakultas Teknik UNJ dapat dikategorikan cukup baik untuk manajemen stress, manajemen perubahan yang terjadi, dan memiliki acuan tujuan positif. Namun demikian masih terdapat sebagian mahasiswa belum memiliki kesadaran diri terutama dalam manajemen waktu terutama dalam mengatur jadwal dan dirinya pada kegiatan akademik dan non akademi

2. Untuk Kemampuan interpersonal skill mahasiswa Fakultas Teknik UNJ dapat dikategorikan cukup baik, seperti kemampuan memotivasi, kemampuan presentasi, kemampuan berkomunikasi, kemampuan membuat relasi. Sementara yang harus menjadi perhatian adalah kemampuan memimpin / teamwork dan kemampuan berbicara di depan umum.

Berdasarkan hasil tersebut, maka dalam upaya meningkatkan softskill mahasiswa diperlukan pelatihan seperti character building dan memasukan mata kuliah softskill sebagai bekal untuk mempersiaplan lulusan agar memiliki kemampuan softskill yang diharapkan dunia kerja. 


\section{Daftar Pustaka}

Amstrong, T. (2004). Menerapkan Multiple Intelligences di Sekolah (alih bahasa Yudbi Murtanto). Bandung: Penerbit Kaifa PT. Mizan Pustaka.

Catur. (2009). Indikator Softskills. http:/ / catur.dosen.akprind.ac.id/200 9/01/19/indikator-soft-skill/ diunduh tanggal 10 Juni 2012

Goleman, Daniel. (1995). Emotional Intellegences: Why It Can Matter More Than IQ. New York: Macmillan Publishing Company.

Hayes, John. (2002). Interpersonal Skills. New York: Routledge.

Klaus, P. (2007). The Hard Truth About Soft Skills: Workplace Lessons Smart People Wish They'd Learned Sooner. New York, US: Harper Colling Publishers.

Sailah, Ilah. (2008). Pengembangan Softskill di Perguruan Tinggi. Jakarta: Direktorat Jenderal Perguruan Tinggi.

Sharma, A. (2009). Professional Development for Teachers. Distasi 30 Juli 2010 dari http://schoolofeducators.com/2009/ 02/importance-of-soft-skillsdevelopmentin-education.
Patrick S O'Brien. (1997). Making College Count: $A$ Real World Look at How to Succeed in and After College.

Putra, Ichsan S. (2005). Sukses Dengan Softskills. Bandung: ITB Press.

Puliam, M. G. (2008). Skill Employer Seek. Career Corner, Excelsior College. Distasi $30 \quad$ Juli 2010 http://www.excelsior.edu/Excelsior College/Publications/SkillsEmployer sSeek16.pd.

Ruben, B. D. and DeAngelis, J. (1998). Succeeding at work: Skills and competencies needed by college and university graduates in the work place. Papper presented at the Total Quality Forum, VIII Transforming Our Organizations through University/Industry Collaboration, University of WisconsinMadison, October 21-22, 1998.

Sultoni. (2008). Soft Skill Building Training. Malang: School of Bussines (SOB).

Wicaksan, Simri. (2010). Softskills. iwayan.info/.../Softskills/MateriKelasSof tSkill_ver100 diunduh tanggal 10 Juni 2013. 